\title{
Exploring the retention of students studying higher education at partner colleges.
}

Colin Wood, Herefordshire and Worcestershire Lifelong Learning Network, Worcester, United Kingdom

\begin{abstract}
The study considers the retention of 708 students studying for higher education awards at further education colleges in 2008-2009. The study challenges the relevance of literature on retention at higher education institutions, to students studying at partner colleges. Using data provided on registration and end of year status, the study considers individual factors identified by Yorke \& Longden (2008) that relate to withdrawal in the first year of study. The findings of the study suggest that the diversity of students and high degree of variability between courses, means that the institutional habitus (Thomas 2002) of partner colleges is highly contextual. Consequently, the relationship between individual factors and withdrawal is seen as both complex and contextual.
\end{abstract}

Keywords: retention; partner colleges, higher education, further education 


\section{Introduction}

This study uses an analysis of a broad area of literature on retention to consider the end of year status of a sample of 708 students who began studying for higher education awards at further education colleges in 2008-2009. The sample was drawn from further education colleges that were both members of the Herefordshire and Worcestershire Lifelong Learning Network and partners of the University of Worcester.

The study considers the international literature on retention. This is a well-established field of study and includes a number of influential long-term studies as well as numerous case studies and theoretical analyses. Much of the early research considers retention in US colleges, with significant contributions by Zepke and Tinto. More recently these approaches have been adapted to consider retention in other countries, and have been given prominence by increasing debate about the future funding of higher education. Within the UK, large scale and theoretical studies by Yorke and Longden have been influential in considering the scale of non-completion of studies, the motivations of students, and the effectiveness of strategies for increasing retention. In recent years their work has been significantly augmented by a number of reports commissioned by the UK government to establish empirical data, to look at specific aspects of retention, and to consider the effectiveness of a range of interventions.

Despite a considerable depth of literature concerning both student retention and student attrition in higher education in the United Kingdom, there is little research on retention within higher education courses delivered at further education colleges in partnership with higher education institutions. This is somewhat strange as the National Audit Office (2007) identifies higher retention rates where higher education is delivered through partner colleges, than where it is delivered at higher education institutions. The same analysis also informs an 
earlier study by the Quality Assurance Agency for Higher Education (2006), which considered areas of good practice in higher education delivered at further education colleges.

These two reports provide the starting point for the consideration of the retention and attrition rates of students studying higher education programmes at partner colleges, and for considering whether direct comparisons with students studying at higher education institutions are justified, given significant differences in the range, delivery and organisation of higher education programmes, and the types and motivations of students.

\section{Research into retention in higher education}

The literature on student retention in higher education, both in the UK and internationally, is broad and diverse. Zepke et al. (2006) divide the literature into an integrationist discourse, deriving from the work of Tinto, and an adaptive discourse, broadly based on Bourdieu (1973). They suggest that integrationist authors such as Yorke and Longden consider early withdrawal and non-completion as being primarily linked to difficulties that students face in integrating into studying and characteristically advocate early support in helping students to adapt to the institution. However Zepke et al. (2006) suggest that the adaptive discourse rejects this analysis, considering early withdrawal and non-completion as primarily linked to institutional biases that preference students with particular backgrounds. Here authors such as Thomas (2002) and Zepke et al (2006, 2007) argue that increased diversity in the student population requires greater institutional adaptability and inclusivity.

Whilst the bipartite nature of the literature can itself be questioned, the categorization by Zepke et al. (2006) allows consideration of two broad schools of thought: first, where retention reflects student difficulties in adapting to studying at higher education level; and 
secondly where the nature of much of higher education makes it more difficult for some types of students to succeed.

As the integrationist approach is commonly described as the dominant paradigm, it is considered first. Tinto (1975) develops the student integration model to consider the reasons for student attrition. This model draws on earlier work by Spady (1970, 1971), which in turn is influenced by Durkheim's theory of suicide (1952). The student integration model considers that the personal characteristics of students influence their initial commitment to the goals of studying and the institution, from then on (primarily in the first year of study) social and academic experiences lead to greater or lesser integration, which ultimately leads to the student's re-evaluation of their commitment to the goals and the institution. Thus whilst the student integration model is based on the interaction of a complex range of factors over a period of time, at essence it is based on the assumption that students withdraw from higher education because of a failure to integrate, which leads to a sense of social dislocation or 'anomie'. Tinto’s later works (Tinto 2000, 2002, 2003) advocate the development of learning communities to enhance the process of academic and social integration and this has been a dominant theme in retention literature.

In a large study Yorke \& Longden (2008) consider the perceptions of first year students across 23 institutions in the UK. They conclude that the first year student experience has been relatively unchanged since a previous survey in 1997 (Yorke et al. 1997) despite policy changes in favour of widening participation in higher education. In their survey Yorke \& Longden (2008: 22) identified 7 major factors that influence retention: poor quality learning experience; not coping with academic demand; wrong choice of field of study; unhappy with location and environment; dissatisfied with institutional resourcing; problems with finance 
and employment; problems with social integration. However they also found that the relative importance of these factors varied according to a number of factors including: age, gender, ethnicity, socio-economic status, number of dependents, qualifications on entry, living at home and subject area. Their findings were, broadly, that

- young students choose programmes less well than older students.

- young students are more likely than older students to be unhappy with various aspects of the geographical environment in which they live and/ or study.

- older students tend to be more critical than younger students of their experience in higher education.

- older students have greater problems with finance, with the demands of part-time study, and with the needs of dependants.

- students from managerial and professional backgrounds are less likely to experience financial difficulties than those from other socioeconomic groups.

Assitera \& Gibbs (2007) also look at the experience and motivation of students who leave higher education. Their principal finding is that most students share "a discomfort with the implicitly understood conception of identity assumed for those who benefit from higher education" whether this be the idea that it is a gateway to higher income, or a natural progression from school. Most of those interviewed doubted themselves in some way - their ability to succeed; their sense of self-worth or the appropriateness of HE for them. Many respondents consider that they are 'keeping up appearances' and were unsure of what they wanted for themselves.

Assitera \& Gibbs (2007:90) conclude that,

"If the student does not have inner motivation to succeed in HE perhaps because s/he is not clear what s/he does want to study at university, or because, deep down, $\mathrm{s} / \mathrm{he}$ is not 
clear that s/he wants to study at university at all, then it can be a deeply unsatisfactory experience. If, by contrast, the inner motivation is there, but it is so high as to be unrealistic, then the experience, again, can turn out to be deeply unsatisfactory”.

The integrationist strategy of targeted support, monitoring and early intervention for those at risk of withdrawal, also informs a case study at the University of Glamorgan, where Bowen et al. (2005) consider how the effective monitoring of attendance, through electronic swipe cards, allows better targeting and earlier intervention for students who may be struggling academically or with their integration into academic life. They suggest that the analysis of electronic monitoring records allows 'global monitoring' of different groups, modules and departments. They find that students are broadly in favour of attendance monitoring, and suggest that improved monitoring may minimize the personal and financial impacts of student withdrawal. This approach also informs the development of bridging courses. Knox (2005) considers the impact of students in further education completing a level 4 credit-rated generic module in order to ease the transition into higher education. The research indicates that of the students who completed the bridging course only $4.9 \%$ left university without an exit award. This compares favourably with studies by Hatt \& Baxter (2003) who found that only $48 \%$ of BTEC entrants left higher education with a degree.

Whilst noting the predominance of the integrationist approach in theory and policy, it is noticeable that there is a growing literature, largely based in Australia and New Zealand, which takes issue with the assumptions, theories and policies of the integrationist approach. Representative of this is Zepke \& Leach (2007) who question three assumptions within the integrationist approach to retention: that government accountability measures can improve the quality of provision and subsequently retention; that institutions, by improving the quality of learning and teaching, can stem early departure; and thirdly, that retaining students in tertiary education is a good thing. They suggest that the effect of auditing retention may be to 
encourage HE providers to refuse admission to students seen as uncertain stayers, also that strategies targeted at reducing non-completion may be unsuccessful as the decision to withdraw early is influenced by factors other than institutional performance. Finally they question the implications of a discourse that considers students who leave early as having failed, even though, from a student's point of view early departure may seem a success.

In an earlier New Zealand study, Zepke et al. (2006) found that learner-centredness improves retention where students feel they belong in an institutional culture, where they experience good quality teaching and support for their learning and where their diverse learning preferences are catered for. The study develops Bourdieu's theory of social reproduction (Bourdieu 1973) to develop an adaptation discourse in which students are seen as having diverse goals and cultural capital. Consequently, some students, who by virtue of their ethnicity, age, gender and/or socio-economic status do not share in the prevailing habitus, find themselves in unfamiliar and possibly alienating situations. The study concludes that institutions cannot realistically expect all students to integrate into the culture of study, without adapting the values and practices of the institution to accommodate a wider range of students.

Thomas (2002) notes that although participation in higher education has widened significantly, the proportional figure for non-completion has remained relatively stable, and that whilst the rate of non-completion was 13\% (in Great Britain) in 1982/3, it had only risen to $17 \%$ (in the UK) in 1997/8. Her analysis considers how well the institutional habitus of higher education suits the needs of a more diverse intake of students. Thomas (2002:438) suggests that the institutional habitus of HEIs determines the practices of the university, for example, flexibility, willingness to change and the extent to which it embraces or suppresses 
diversity, and that this has a relationship on the retention of 'non-traditional' learners. Her findings are that such an institutional habitus is perceived by students through staff attitudes, teaching and learning, accommodation, social spaces and opportunities for participation and that from these perceptions students judge the inclusivity of the institution. She argues that higher education institutes must examine their internal structures of power and representation, including the spheres of governance, curricula and pedagogy.

Whilst integrationist and adaptive discourses disagree on many elements, there is a shared understanding that large numbers of students withdraw from all forms of higher education without completing their awards, and that this provides an imperative for change in higher education practices. It is also evident from statistical studies of retention in the UK (QAA (2006), NAO (2007)) that there are important differences between the student experience and the institutional treatment of higher education students studying at further education colleges and at higher education institutes. Thus it seems appropriate to consider whether there are differences in institutional habitus between further education and higher education institutes, whether such differences might provide reasons for early withdrawal, and whether it is appropriate to transfer policies and practices between different types of institution.

\section{The background to higher education in further education colleges}

Parry \& Thompson (2002) lay out the history of the development of higher education in further education, including analysis of the Dearing report (1997), the Learning and Skills Act 2000 and the issues of funding through HEFCE and LSC. They identify a territory of considerable complexity, where the uneven distribution of provision is highly influenced by the historical and local factors and by definitions and distinctions which worked against rational and coherent approaches to higher education provision. They see that the 
development of foundation degrees as vocationally oriented higher education and the introduction of ambitious targets for the proportion of 18-30 year olds who have participated in higher education, provides a policy context for an increased role for further education colleges. This reverses a history where higher education in further education colleges was overshadowed by polytechnics in the 1980s and then limited by highly restrictive quality procedures in the 1990s. Parry \& Thompson (2002) consider the importance of the Dearing report (1997) and its implementation by the new Labour government, which raised the priority of growth of higher education in further education as part of its policy on lifelong learning.

More recently, QAA (2007) found that in 2006-2007 there were some 96,000 students enrolled onto higher education programmes at 270 colleges in England, and that there were 89 HE institutions and EdExcel awarded HE qualifications funded by HEFCE and delivered through colleges in England. The QAA academic review of HE in FE identified good practice in academic standards and in the quality of learning opportunities.

Department for Business, Innovation and Skills (2009) reviewed the role and future of higher education. Within this, the paper considers the 'vital role' of FE colleges in delivering HE, especially in vocational and technical subjects, and its importance for widening participation in higher education. The report concludes that decisions around HE in FE should be driven by learner and employer choices, rather than governmental targets.

Bathmaker et al. (2008) substantially agree with the complicated structure of FE described by Parry \& Thompson (2002). However they identify HE in FE as a 'dual-sector' with complex interrelationships between providers and significant issues of boundaries and progression. They suggest that there has been a lack of coherent policy around HE in FE, and that much of 
the lead for policy development has come from higher education institutions and consequently provides a strong role for HEFCE and a lesser role for the LSC. However they conclude that the barriers between HE and FE are 'permeable and workable' and that this permits a broad range of relationships.

The complexity of relationships between HE institutes and FE colleges is considered by West (2006) and Foskett (2005). West (2006) considers the complex boundaries between higher education and further education, suggesting that the key differences are in the accreditation arrangements and qualifications frameworks, where HE institutions have a high degree of autonomy, whilst FE colleges have greater external scrutiny. In a case study on the collaborative development of a foundation degree, Foskett (2005) recognizes the complexity of the relationships between HE Institutions, FE colleges and employers and concludes that successful collaboration provides benefits to all parties, but must be managed in a flexible manner that develops equity and trust between organisations.

DIUS (2009) considers the financial issues around studying higher education in FE colleges and in HE institutions. The research finds that there was little difference between students incomes, however that students at FE colleges relied more on income from paid work and less on contributions from family and friends. In addition the research found that students at FE colleges had smaller student loans and much lower borrowing levels than those at $\mathrm{HE}$ institutions. Despite these differences, the value of HE study at FE colleges is strongly supported by students. Yorke and Longden (2010) surveyed 474 students studying part-time Foundation degrees at a range of institutions, and found that most part-time students are positive about their experience and that they have gained in practical, academic and psychological terms, in line with the expectations for Foundation degrees. 
Much of the preceding discussion is based on a central premise that FE colleges' main role in higher education is in the provision and collaborative provision of vocational programmes. This premise is rarely critiqued; indeed it appears as a tenet of policy (DBIS 2009:104). This is somewhat at odds with the policy and literature which identifies the importance of FE colleges in widening participation in HE (Stanton et al. 2008). Indeed it seems probable that much of the diversity identified by Bathgate et al. (2008) reflects different responses by FE colleges to the pressures and opportunities that come from these two policy agendas. Similarly, that the practical complexity of combining FE specialisation on vocational programmes with political and financial encouragement for FE colleges to include larger proportions of underrepresented groups than $\mathrm{HE}$ institutions will tend to produce an increasingly complicated pattern of provision.

\section{Retention where higher education is delivered in further education colleges}

The QAA (2006) reviewed 105 HE courses at 76 FE colleges in 2003-2005. The report identifies considerable good practice with generally good rates of progression. It produces two conclusions with regard to retention: first, that HE taught in FE Colleges has higher levels of student retention when central services and subject staff contribute through their support of students from their admission to the completion of their programmes. Second, that formal tutorial arrangements contribute to a high level of student retention.

The identification of collaboration between central services and subject staff points to structural differences in recruitment and admissions processing between Higher Education Institutes and Further Education colleges. The report sees an emphasis within further education colleges on identifying and understanding different students' abilities before the beginning of the programme to ensure that support is available. 
QAA (2006 para 55) suggests that 'effective practice includes the close monitoring of the students most at risk of leaving the programme prematurely, particularly in the first few weeks', and that good practice at FE colleges includes providing "frequent formal and informal opportunities for students to discuss their general progress and voice any concerns” (QAA 2006 para 56) although the report identifies that colleges are often better at providing informal opportunities that timetabled sessions. Indeed the report found that in over half of the reviewed courses, retention and progression were higher where formal tutorial arrangements were in place.

QAA (2006 para 59) found that a majority of programmes recorded progression rates in excess of 70 per cent from the end of year one to the start of year two, and that progression routes had increased substantially in recent years. This has led to increasing numbers of students progressing to further study.

The National Audit Office (2007) in their report into retention in Higher Education, 'considers both the continuation rates (student progression from level 4 to level 5) and completion rates (student completion of awards) of a sample of HE providers. The report considers both full-time and part-time provision. Whilst much of the report includes students in FE Colleges within the analysis and recommendations for all students, it does identify a number of areas where there are notable differences.

In considering all HE providers, the report finds that compared internationally, higher education in England achieves high levels of student retention, with 90.6 per cent of full-time 
students continuing into a second year of study. This includes 91.6 per cent of those studying for a first degree and 61.9 per cent of part-time students (National Audit Office 2007:15).

National Audit Office (2007) (using HESA data from 2005-06), found that of the 1.3 million undergraduates who commenced their studies in 2004-05, 28,000 full-time and 87,000 parttime undergraduates were no longer in higher education in 2005-06. This equates to an overall non-continuation rate for students in their first year of study of around 9\% for 200405. Their analysis of the HESA data demonstrates that of those starting courses in 2004-05: 90.6 per cent of full-time students continued into a second year of study (including 91.6 per cent of those studying for a first degree); and 61.9 per cent of part-time students continued into a second year of study (including 76.9 per cent of those studying for a first degree). National Audit Office (2007:15) also identify the percentage of full-time HE students expected to complete their course, and finds that this is around $78.1 \%$ in England based on undergraduates who commenced their studies in 2004-05.

Their statistical analysis indicates that variations in retention between subjects and types of institution are largely due to the characteristics of students, including their level of pre-entry qualifications. The research identifies differences in retention between institutions and course areas, but finds that four factors explain over 70 per cent of the difference between institutions in the proportion of full-time students continuing to a second year of study (National Audit Office 2007:19). Thus continuation to the second year of study is higher for institutions which:

- recruit more students from neighbourhoods with higher rates of participation in higher education

- admit students with higher pre-entry qualifications 
- have a smaller proportion of their intake aged 21 or over

- offer particular subjects - particularly Education, Medicine and Dentistry, subjects allied to Medicine and the Creative Arts

Aside from differences in provision, they find that the factor most affecting a student's chance of continuing is whether they are studying full time or part-time, with full-time students being much more likely to continue if other factors are held constant. However National Audit Office (2007:19) finds that,

Part-time students registered with a higher education institution for a course which is taught in a further education college are more likely to continue than those in higher education institutions, whereas the opposite is true among the full-time cohort.

This important finding suggests that there may be a significant difference either in the type of students studying part-time higher education courses, or in the institutional arrangements and provision of higher education courses between FE colleges or higher education institutes.

Taken together, the two reports find a wide range of HE provision within Further Education colleges in the UK, with many examples of good practice, but that overall retention rates are lower for full-time students at further education colleges than those studying higher education programmes at higher education institutes. By contrast they find that the retention of parttime students is higher in further education. Broadly, the findings of the National Audit Office (2007) confirm US and UK studies on the reasons for early withdrawal, with most withdrawals related to personal reasons, although it does identify a difference in student attitudes towards teaching staff and contact time that may account for some difference in student withdrawal. 


\section{Withdrawal rates within a sample of partner colleges courses}

Following analysis of documents from the Higher Education Institution, the research sought to consider whether the type of course and its place of delivery affect retention for full and part-time students studying higher education programmes at partner colleges using a sample of all types of courses. The sample was derived from courses delivered at partner colleges that were also members of the Herefordshire and Worcestershire Lifelong Learning Network. The sample was originally developed for a large scale study of regional progression (Obrey \& Wood 2011), and was a cluster sample based on subject areas that reflect the balance of provision across the region. The sample included 708 students on 29 undergraduate programmes across 8 partner colleges. Data was based on end of year status for the year 2008/2009 including course information, and student level data given on registration to the institution. Data with missing fields was removed from the sample. Thus the sample is broadly representative of students registered onto courses with collaborative provision for the year 2008/2009, where there was direct funding to the partner college.

There is one important caveat to the data analysis in this section. The approach used is not the same as that used for HESA data analysis. The analysis in this research is based on the much simpler assessment of student status at year end, and thus inevitably includes a small number of students who may not have ceased studying. In consequence the data is used within this report for comparison but should not be interpreted as equivalent to HESA data.

Table 1. Full-time student status at end of 2008/09

\begin{tabular}{|c|c|c|c|c|c|}
\hline Year of study & $\begin{array}{c}\text { Current/ } \\
\text { Continuing }\end{array}$ & $\begin{array}{c}\text { Left Normal } \\
\text { Completion }\end{array}$ & Intercalating & Withdrawn & $\begin{array}{c}\text { Grand } \\
\text { Total }\end{array}$ \\
\hline 1 & $72 \%$ & $2 \%$ & $2 \%$ & $24 \%$ & $100 \%$ \\
\hline 2 & $22 \%$ & $63 \%$ & $2 \%$ & $12 \%$ & $100 \%$ \\
\hline 3 & $10 \%$ & $74 \%$ & $2 \%$ & $14 \%$ & $100 \%$ \\
\hline Grand Total & $48 \%$ & $31 \%$ & $2 \%$ & $19 \%$ & $100 \%$ \\
\hline
\end{tabular}


The recorded status of students at end of year 2008/09 shows that most students are proceeding towards completion of their award. However within the sample of 708 students, 137 students withdrew in this academic year without completing their award. This equates to 19\% of HE students studying at further education colleges in 2008/09. This overall rate needs to be approached with caution, as students recorded as withdrawing from the course may not mean that they have ceased studying altogether. In addition, the rate includes students across all years of study, as well as part-time and full-time students. Thus the overall withdrawal rate obscures large differences in retention between course types and subject areas; by personal factors such as gender, ethnicity, socio-economic, disability and cultural factors, as well as practical factors such as distance from home and mode of study.

In common with previous studies, the data shows the highest rates of withdrawal in the first year of study. The data shows that $24 \%$ of first year students withdrew before the end of the academic year and that the rates of withdrawal for 2nd and 3rd year students are considerably lower at around 15\%. $79 \%$ of students in 2008/09 appear to be studying for or have completed their HE studies, and that around $2 \%$ of students have chosen to intercalate. Intercalation remains fairly constant at around $2 \%$ across the three years, although this varies somewhat for part-time and full-time modes of study. Whilst the final status of intercalating students is unknown, it indicates a stated intention to continue studying at the time of leaving. Thus the rate of intercalation may reflect changes in student circumstances, rather than discontent with the course. The percentage of students withdrawing from $\mathrm{HE}$ in FE programmes decreases from year 1 to year 3. Thus whilst $24 \%$ of all first year students withdraw, those who complete the first year are less likely to withdraw in the subsequent years. However the rates of $15 \%$ and $14 \%$ in years 2 and 3 remain high compared to national averages. 
Table 2. Part-time student status at end of 2008/09

\begin{tabular}{|c|c|c|c|c|c|}
\hline Year of study & $\begin{array}{c}\text { Current/ } \\
\text { Continuing }\end{array}$ & $\begin{array}{c}\text { Left Normal } \\
\text { Completion }\end{array}$ & Intercalating & Withdrawn & $\begin{array}{c}\text { Grand } \\
\text { Total }\end{array}$ \\
\hline 1 & $73 \%$ & $0 \%$ & $2 \%$ & $25 \%$ & $100 \%$ \\
\hline 2 & $27 \%$ & $52 \%$ & $3 \%$ & $18 \%$ & $100 \%$ \\
\hline 3 & $50 \%$ & $50 \%$ & $0 \%$ & $0 \%$ & $100 \%$ \\
\hline Grand Total & $47 \%$ & $30 \%$ & $3 \%$ & $21 \%$ & $100 \%$ \\
\hline
\end{tabular}

Methodological differences make exact comparison impossible, however these findings compare favourably with the NAO (2007) as they suggest that between $79 \%$ and $81 \%$ of students in the sample studying HE in FE are expected to complete their course. Indeed as the NAO findings are based on full-time students, it would be reasonable to expect that the sample would be considerably below the national average.

The high rate of first year withdrawals reflects widespread findings within international retention research, where issues of socialization, unrealistic expectations of higher education and failure to adapt to full-time Higher Education study lead to high rates of withdrawal during the first year of study. However the QAA (2006) study suggest that full-time students who study HE at an FE college are less likely to leave in the first year than those studying at University, as they commonly progress from the same institution and are more likely to be living at home. This does not seem to be supported by the findings of the report.

In considering the status of part-time students at the end of academic year 2008-2009, it is noticeable that the overall withdrawal rates are lower than those for full-time students, and this is especially noticeable in the second year of study, where they show a very different pattern from that of full-time students.

\section{Withdrawal of first year undergraduates in the sample of partner college courses}

As the first year is widely identified as the most important period for student retention, the study considers withdrawals of first year undergraduates within the sample. This produces a 
subgroup of 355 first year undergraduates studying on 23 higher education courses run wholly or in part at further education colleges within the region. The findings provide a snapshot of HE in FE provision in 2008/09 with a range of new and old courses, courses that are closely aligned with FE provision and courses that do not have close links. Some programmes are run as collaborative programmes whilst the running of others is more independent of the higher education institution.

The study was not able to consider 7 major factors that influence retention identified by Yorke \& Longden (2008: 22): poor quality learning experience; not coping with academic demand; wrong choice of field of study; unhappy with location and environment; dissatisfied with institutional resourcing; problems with finance and employment; problems with social integration. Instead the study looked at the variable factors that Yorke \& Longden (2008) identify as important. The study looks at: age, gender, ethnicity, socio-economic status, qualifications on entry. The data is then used to identify whether there are correlations between these factors and student withdrawal in the first year of study. In addition the study looks at cohort size and mode of study.

Before considering the factors influencing retention, it is important to identify some patterns of participation. The sample provides an interesting perspective on the students who study higher education courses at further education colleges. Within the sample the overall proportion of female to male students is $56: 44$, with a marked difference between full-time students, where the ratio female to male students is 49:51 and part-time students where less than a quarter of students are male. The average age on entry of students within the sample is 27.5 years, and the standard deviation is 11.4 years. However the distribution is heavily skewed with $49 \%$ of students aged $18-21$ years on entry Ethnicity within the sample was very uniform with $90 \%$ of first year students giving their ethnicity as 'White British' and 
'White Other' and another 4\% not giving any data on ethnicity. Students within the sample had a wide range of educational backgrounds, nearly $39 \%$ of entrants listed Level 3 vocational qualifications as their highest qualification on entry, however there were $17 \%$ with qualifications at level 4 and above, and $13 \%$ of students with no formal qualifications. All socio-economic groups were represented in the sample, however the best represented group (23\%) was Lower managerial \& professional occupations.

The overall withdrawal rate for undergraduate first year students studying $\mathrm{HE}$ at an FE institute in 2008-09 was $24 \%$ and intercalation accounted for $2 \%$. The withdrawal rates for full-time students (24\%) and part-time students (25\%) are broadly similar. In addition, there are clear differences between male and female withdrawal rates and patterns of withdrawal. The first year withdrawal rate for female students was $24.5 \%$, and for male students was $27 \%$.

Within the sample of 23 courses there are a range of different awards. Whilst the data shows elevated rates of withdrawal for HNC programmes the data is only based on 9 students. Interestingly the withdrawal rates for HND and Foundation degree programmes show considerable difference. Although the sample size is larger it should be noted that the rates for HNDs may be distorted upwards by one HND programme that had significant problems and was discontinued shortly after the study period.

Table 3. Withdrawal rates by award type

\begin{tabular}{|c|c|c|c|}
\hline Award type & No of courses & No of 1st year students & Withdrawals rates \\
\hline Cert HE & 1 & $4(1 \%)$ & n/a \\
\hline HNC & 1 & $9(3 \%)$ & $27 \%$ \\
\hline HND & 12 & $191(54 \%)$ & $22 \%$ \\
\hline FD & 7 & $113(32 \%)$ & $15 \%$ \\
\hline BSc & 2 & $38(11 \%)$ & \\
\hline Total & 23 & 355 & \\
\hline
\end{tabular}


The study considered the impact of the size of first year cohorts on withdrawal rates. The research was based on 23 courses with a total of 355 first year students. Cohort sizes range from 1 to 39, with a mean cohort size of 15.4 and a standard deviation of 11 . There are 9 courses with less than 10 students, and 4 courses with more than 25 students. Given that the overall withdrawal rate for the first year sample was $24 \%$, the data shows a high degree of variation in the withdrawal rates across the range of cohort sizes, with one clear outlier. When grouped, the withdrawal rate for cohort sizes of $0-9$ was $20 \%$ (this is reduced to $13 \%$ if the outlier is excluded), $10-19$ was $27 \%$, 20-29 was $19 \%$, and $30+$ was $33 \%$. Thus whilst cohort sizes appear to show a slight advantage to studying within very small cohorts (0-9 students) and medium sized cohorts (20-29 students) this may not equate to class size or have particular relation to staff: student ratios.

Although cohort size provides an indication of the social aspects of the student experience, it must be acknowledged that module course structures do not necessarily mean that students in small cohorts will be taught alone, indeed often there is considerable shared content between courses. This also applies to students registered on part-time and full-time programmes who may well study together.

Figure 1.First year withdrawals and cohort size

Modes of attendance were not considered on their own as there was a clear link to both gender and age. Within the sample of 355 first year students, 254 (71.5\%) were registered as full-time, whilst 101 (28.5\%) students were part-time. The proportion of male and female students differs considerably with mode of attendance, with roughly equivalent numbers of male and female students studying full-time, but a 3:1 ratio of women to men in part-time studies. 
Table 4. Proportion of full-time and part-time students by gender

\begin{tabular}{|c|c|c|c|}
\hline Mode of Attendance & \% Male & \% Female & Total \% \\
\hline Full- time & $51 \%$ & $49 \%$ & $100 \%$ \\
\hline Part-time & $24 \%$ & $76 \%$ & $100 \%$ \\
\hline
\end{tabular}

These distinctions are further complicated when the genders of students are considered within age bands. Here it is apparent that despite an overall proportion of female to male students of 56:44. Within the largest age band (18-21) over $61 \%$ of male students are between $18-21$ on registration, whilst only $39 \%$ of female students are in the same age range. By contrast $41 \%$ of female students are over 30 years, whilst only $16 \%$ of male students are in the same age range.

Figure 2. Age group and gender on entry to higher education study at a partner college

When presented graphically the patterns suggest that participation in higher education programmes gender is significantly affected by age and gender. This shows a different distribution for full-time students with a higher proportion of older female students, whilst there are very few full-time male students over 40 . The differences are more pronounced for part-time students with a large proportion of women studying between the ages of 22 to 50 . 
By contrast the proportion of male part-time students increases from 5\% in the 22-30 age range to $40 \%$ of male in the age range $40-50$.

Figure 3. Percentage of withdrawals in the first year by age and gender

The differences in the age and gender of students, is also visible in the first year withdrawal rates. The first year withdrawal rate for female students was $24.5 \%$, and for male students was $27 \%$. The breakdown by age groups shows that female rates of withdrawal in the first year of study are lower than male for all age groups except 18-21. However as the 18-21 category accounts for $61 \%$ of male students and $36 \%$ of female students, this has limited impact on the overall rate. However it is notable that the highest rate of withdrawal for female students occurs where the ratio of male and female students is highest.

The link between highest qualifications on entry and retention is fairly clear, with the high withdrawal rates amongst those with unknown qualifications or no formal entry qualifications. It seems likely that these categories include overseas qualifications as well as mature students returning to education, and that aspects such as unrealistic learner expectations and inability to adapt may be a significant factor. It is also noticeable that the findings reflect the findings of the 3 year study into the same sample of courses by Obrey \& Wood (2011) which showed higher withdrawal rates for students whose highest qualifications on entry were vocational courses and level 4 and above than for students with A and AS levels.

Table 5. Proportion of highest qualification on entry 


\begin{tabular}{|c|c|c|}
\hline & Percentage of students & Withdrawal rate \\
\hline Level 3 A/AS Level & $19 \%$ & $15 \%$ \\
\hline Level 3 Vocational Qualification & $39 \%$ & $32 \%$ \\
\hline Level 3 Not Known & $10 \%$ & $19 \%$ \\
\hline Level 4 or Above & $17 \%$ & $23 \%$ \\
\hline No Formal Entry Qualification & $13 \%$ & $28 \%$ \\
\hline Not Known & $3 \%$ & $66 \%$ \\
\hline Grand Total & $100 \%$ & \\
\hline
\end{tabular}

A brief review of the students' last place of study was conducted to see whether there was a link to progression within the same institution, however only $14 \%$ of students were progressing from courses at the same institution, and there was no apparent link between this and the retention rate.

The data on ethnicity was assessed, but is considered insufficient to support conclusions, and is included subject to caveats. From student registration data, $90 \%$ of first year students gave their ethnicity as 'White British’ and 'White Other' and 4\% did not give any data on ethnicity and are listed as 'Not known'. The remaining $6 \%$ of students gave a range of other ethnicities. Of these around a quarter were overseas students on a one year programme. Of the remaining students only $50 \%$ were continuing with their studies at the end of the year 1 . Whilst this appears unduly high, and deserves further consideration, the total number of withdrawals is too small to draw statistical conclusions.

Students studying HE in FE provided information on their highest qualification on entry. The data shows a high proportion (39\%) of Level 3 vocational qualifications and notably high rates of level 4+ qualifications (17\%) and no formal entry qualifications (28\%). This suggests that there may be 2 separate processes at work: progression from L3 vocational qualifications, and the reskilling of career changers. However withdrawal rates are high in 
these three categories, suggesting that there may be particular retention issues for these types of students.

The final category considered was the socio-economic group of students. Socio-economic group is data collected on entry to courses, but is self-reported. Consequently it seems likely to be significantly skewed. Analysis of responses shows that $52 \%$ of $18-21$ year olds list themselves in the top three categories, and that $18-21$ year olds account for $64 \%$ of all higher managerial \& professional occupations, 53\% of all intermediate occupations and 56\% of all lower managerial and professional occupations. This seems an unlikely career trajectory and disproportionate to the data on highest entry qualifications and consequently is considered to have little credibility.

\section{Discussion}

Despite the small sample size and detailed data, it is very difficult to draw clear conclusions about the factors that affect retention within the sample. Indeed the findings show that students studying higher education at partner colleges are a very diverse body with numerous sub-groups. In addition the data is somewhat fluid, with courses rising and falling in popularity and quality, with changes of institutional and inter-institutional strategy, with changes to staffing and delivery times, as well as to less obvious changes in the way that students engage with their studies and are supported in the transition into higher learning. It seems likely that the factors Yorke \& Longden (2008: 22) identify cannot be easily generalised across this type of sample, and that the best that we can achieve is to see patterns of behaviour and contributing factors. Indeed it seems likely that the very complexity of the social and educational milieu may itself contribute to the retention of students. However two findings are very clear: that gender and age cannot be disentangled within the analysis of 
retention and that any attempt to do so risks oversimplifying the range of learners and learner motivations; and that cohort size has little meaning within the context of higher education in partner colleges. These findings suggest that gender and age are both factors in early withdrawal from $\mathrm{HE}$ in $\mathrm{FE}$, but that the patterns of age and gender distribution are highly complicated and deserve further study.

Whilst the inability to disentangle the contextual complexity of higher education in partner colleges from the factors influencing individual choices to withdraw from that study may appear to be a somewhat post-modernist quandary - it is an important task. Indeed the need to fully understand that partner colleges may be more complicated than Universities is central to study in this area. It cannot be underestimated how the habitus of HE studying is more fluid within small groups that study in the evenings or study amidst other students who may be decades younger than themselves. The 'learner journey' for a part-time student often appears a lonely journey, surrounded with temptations to stop studying. It seems likely that Thomas's (2002) concept of an institutional habitus that embraces or suppresses diversity through its practices is less relevant than the dynamics of the cohort and the relationships with tutors and institutions. The QAA (2006) suggestion that formal and informal opportunities for students to discuss their general progress and voice any concerns seems to recognise that support within this context is often less about skills development than the development of trusting relationships within the cohort and its teaching team.

Finally, it seems inappropriate to see the withdrawal of first year students as always a bad thing, that students making informed decisions and leaving to take on other opportunities cannot be viewed as an individual or institutional failure. Undoubtedly, the withdrawal rate provides a useful means of assessing programmes and is likely to indicate problems with quality and unrealistic expectations - however it is flawed as an exact measure of the health 
of higher education programmes within further education colleges. Not only is it flawed because of the fluidity of the milieu, but also because for many students starting higher education courses in their local further education college, this is an individual experiment in 'what if...' and fits within the practical demands of the present and aspirations for the future. 


\section{References}

Assitera, A. and Gibbs, G. (2007) Teaching and Training: student retention and motivation. European Political Science: 6, pp. 79-93

Bardagi, M., Hutz, C. (2009)... Was no other way": dropout students" perceptions on leaving higher education - Psico-USF, Vol 14, Issue 1, pp. 95-105

Bathmaker, A., Brooks, G., Parry, G. and Smith, D. (2008) Dual-sector further and higher education: policies, organisations and students in transition. Research Papers in Education, Vol 23, Issue 2, pp $125-137$

Bekhradnia, B., Whitnall, C. and Sastry, T. (2006) The academic experience of students in English universities [online]. Oxford: Higher Education Policy Institute. Available from: www.hepi.ac.uk/pubdetail [25 June 2007].

Bourdieu, P. (1973) Cultural reproduction and social reproduction, in: R. Brown (Ed.) Knowledge, education and cultural change. London: Tavistock, 487-510.

Bowen, E., Price, T., Lloyd, S. and Thomas, S. (2005) Improving the quantity and quality of attendance data to enhance student retention. Journal of Further and Higher Education. Vol. 29, No. 4, pp. 375-385

Caison, A. (2007) Analysis of institutionally specific retention research: A comparison between survey and institutional database methods. Research in Higher Education, Vol. 48, No. 4, pp. 435-451

Department for Innovation, Universities and Skills (2008) Further Education Colleges Models for Success. HMSO

Department for Innovation, Universities and Skills (2009) Student Income and Expenditure Survey 2007 /08 English Domiciled Students Research Report 09/05 carried out by the Institute for Employment Studies and the National Centre for Social Research London accessed on 11.02.11 at http://www.dius.gov.uk/ /media/publications/D/DIUS_RR_09_05

Durkheim, E. (1952) Suicide: A Study in Sociology (Trans. by J.A. SPAULDING and G. SIMPSON), London: Routledge and Kegan Paul

Foskett, R. (2005) Collaborative Partnership in the Higher Education Curriculum: a crosssector study of foundation degree development Research in Post-Compulsory Education, Volume 10, Number 3, 2005

Hatt, S. \& Baxter, A. (2003) From FE to HE: studies in transition: a comparison of students entering higher education with academic and vocational qualifications. Widening Participation and Lifelong Learning, 5(2), 30-41.

HEFCE (2003b) Supporting higher education in further education colleges: Policy, practice and prospects HEFCE Good practice 2003/16 Bristol 
HEFCE (2006) Higher education in further education colleges: consultation on HEFCE policy in HEFCE 2006/48 Bristol

Hughes, G. (2007) Using blended learning to increase learner support and improve retention. Teaching in Higher Education, Vol. 12, No. 3, pp. 349_363

Knox, H. (2005) Making the transition from further to higher education: the impact of a preparatory module on retention, progression and performance. Journal of Further and Higher Education Vol. 29, No. 2, pp. 103-110

Leitch, S. (2006) Prosperity for all in the global economy - world class skills. HMSO London

Longden, B. (2006) An Institutional Response to Changing Student Expectations and their Impact on Retention Rates. Journal of Higher Education Policy and Management Vol. 28, No. 2, pp. 173-187

McQueen, H. (2009) Integration and regulation matters in educational transition: a theoretical critique of retention and attrition models. British Journal of Educational Studies, 57(1), 7088.

National Audit Office (2007) Staying the course: the retention of students in higher education. London: The Stationery Office.

Obrey, D. and Wood, C. (2011) 'Tracking the Entry of Vocational Learners into Higher Education in a Rural Area of England'. In J. Shaw, J. Wise, \& A. Rout (editors) Research in the Lifelong Learning Networks. York: Lifelong Learning Networks National Forum

Parry, G. and Thompson, A. (2002) Closer by Degrees - the past, present and future of higher education in further education colleges LSDA London

Poole, L. \&, Lefever, R. (2009) The Leeds Met book of Resilience. Leeds: Leeds Metropolitan University

Quality Assurance Agency for Higher Education (2006) Learning from higher education in further education colleges in England 2003-05. Mansfield:QAA

Quality Assurance Agency for Higher Education (2007) Higher education in further education colleges in England: Information bulletin2006-07. Gloucester: QAA

Reay, D., Davies, J., David, M. and Ball, S. (2001) Choices of Degree or Degrees of Choice? Class, 'Race' and the Higher Education Choice Process. Sociology Vol. 35, No. 4, pp. 855874.

Spady, W. (1970) Dropouts from higher education: an interdisciplinary review and synthesis, Interchange, 1 (1), 64-85.

Spady, W. (1971) Dropouts from higher education: toward an empirical model, Interchange, 2 (3), 38-62. 
Thomas, L. (2002) Student retention in higher education: the role of institutional habitus. Journal of Education Policy, vol. 17, no. 4, 423-442

Tinto, V. (1975) Dropout from Higher Education: A Theoretical Synthesis of Recent Research. Review of Educational Research; 45: 89-125

Tinto, V. (2000) Taking Student Retention Seriously: Rethinking the First Year of College. NASCADA conference proceedings

Tinto, V. (2002) Promoting Student Retention: Lessons Learned from the United States. Presented at the 11th Annual Conference of the European Access Network, Prato, Italy. June 19, 2002

Tinto, V. (2003) Promoting Student Retention through Classroom Practice. Conference papers: Enhancing Student Retention: Using International Policy and Practice.

Tinto, V. (2006) Research and Practice of Student Retention: What next? Journal of College Student Retention, vol.8, no.1, 1-19

West, J.(2006) Patrolling the borders: accreditation in further and higher education in England. Journal of Further and Higher Education, Vol. 30, No. 1, pp 11 - 26

Yorke, M., Longden, B. (2008) The first-year experience of higher education in the UK. York: Higher Education Academy

Yorke, M. and Longden, B. (2004) Retention and Student Success in Higher Education. Open University Press

Yorke, M. and Longden, B. (2010) Learning, Juggling and Achieving Students' experiences of part-time Foundation degree. Lichfield: Foundation Degree Forward Accessed on 11.02.11 at:

http://www.fdf.ac.uk/downloads/228/20100125164438Yorke\&LongdenReport.pdf

Yorke, M., Bell, R., Dove, A., Haslam, E., Hughes-Jones, H., Longden, B., O’Connell, C., Typuszak, R. and Ward, J. (1997) Undergraduate non-completion in higher education in England [Report 97/29]. Bristol: Higher Education Funding Council for England.

Yorke, M. (1999) Leaving early: Undergraduate non-completion in Higher Education. London: Farmer

Zepke, N., Leach, L. and Prebble, T. (2006) Being learner centred: one way to improve student retention? Studies in Higher Education Vol. 31, No. 5, pp. 587-600

Zepke, N. and Leach, L.(2007) Educational Quality, Institutional Accountability and the Retention Discourse. Quality in Higher Education, Vol. 13, No. 3, November 2007 